УДК 622.274

\title{
К ВОПРОСУ БЕЗОПАСНОЙ ЭКСПЛУАТАЦИИ ПОДЗЕМНОГО ТУРИСТИЧЕСКОГО КОМПЛЕКСА «ЦАРСТВО ВЕЧНОЙ МЕРЗЛОТЫ|»
}

\author{
Петров Андрей Николаевич', \\ petrow_andrei@mail.ru
}

Киселев Валерий Васильевич²,

Романова Елена Константиновна²,

helconst@mail.ru

\author{
Сивцева Алена Ивановна', \\ alyona_archibald@mail.ru \\ Северо-Восточный федеральный университет им. М.К. Аммосова, \\ Россия, 677000, г. Якутск, ул. Белинского, 58 \\ Институт горного дела Севера им. Н.В. Черского Сибирского отделения Российской Академии наук, \\ Россия, г. Якутск, ул. Ленина, 43
}

\begin{abstract}
Актуальность. Исследованиям теплового режима подземных сооружений различного назначения и разработке эффективных способов управления им в последние годы уделяется большое внимание. Это связано не только с интенсификацией освоения подземного пространства, но и с многообразием тепловых условий и степенью влияния температурного фактора на эффективность и безопасность строительства и эксплуатации подземных сооружений. Специфические условия криолитозоны, связанные в первую очередь с наличием многолетнемерзлых горных пород, предъявляют ряд дополнительных требований по безопасности при их строительстве и эксплуатации.

Объекты: штольни туристического комплекса «Царство вечной мерзлоты», расположенного на 5-м км Вилюйского тракта г. Якутска.

Цель: разработка мероприятий по обеспечению требуемого технического состояния, теплового режима и рекомендаций по креплению подземных горных выработок туристического комплекса, обеспечивающих устойчивость выработок и безопасные условия пребывания экскурсантов.

Методы: натурные исследования температурного режима, визуальное обследование горного склона и подземных горных выработок туристического комплекса, выбор рационального типа крепления, расчет параметров крепи, математическое моделирование и численные расчеты температурного режима.

Приведены результаты натурных исследований теплового режима подземных горных выработок туристического комплекса «Царство вечной мерзлоты» в зимний период эксплуатации, результаты визуального обследования горного склона, штолен и камер, и даны рекомендации по обеспечению устойчивости и креплению имеющихся зон вывалообразования. Выполнен расчет температурного режима комплекса "Царство вечной мерзлоты» и требуемой мощности холодильных машин с применением разработанного в лаборатории горной теплофизики Института горного дела Севера им. Н.В. Черского Сибирского отделения Российской Академии наук программного комплекса MuseumCVM. Для сокращения энергозатрат на выработку искусственного холода в летний период рекомендовано проводить ежегодные осенние и весенние хладозарядки принудительной вентиляцией.
\end{abstract}

\section{Ключевые слова:}

Криолитозона, подземные горные выработки, многолетнемерзлые породы, температурный режим горный массив, хладозарядка, глазировка, натурные наблюдения, крепление горных выработок, анкерная и рамная крепь, сопряжение горных выработок.

\section{Введение}

Произошедшие вывалы пород кровли в подземных горных выработках (ПГВ) туристического комплекса «Царство вечной мерзлоты» (ЦВМ) вызвали необходимость разработки превентивных мероприятий по предупреждению аварийных ситуаций. ЦВМ расположен в пригороде г. Якутска в основании Чочур-Муранской гряды в ранее пройденных в 80-х гг. прошлого века ПГВ ледника (подземного холодильника) для хранения замороженного белкового продовольствия. ПГВ были проведены проходческим комбайном избирательного действия типа ГПК
В объемно-планировочном решении ЦВМ (рис. 1) состоит из 2 штолен, сбитых одной сбойкой, и 25 камер, в которых размещены ледовые скульптуры. Длина штольни № 1 составляет 102 м, штольни № $2-124$ м, длина сбойки $21 \mathrm{м}$, сечение выработок неодинаковое и в среднем составляет - штолен 9,3 м², камер $10 \mathrm{~m}^{2}$. Крепление ПГВ, за исключением устьевых частей штолен, не производилось. В зимний период ПГВ принудительно вентилируются холодным воздухом, нагнетаемым вентилятором, и их поверхности покрываются слоем ледяной глазировки толщиной 50 мм путем набрызга тонкораспыленной воды, обеспе- 
чивая тем самым хладозарядку вмещающего горного массива (ГМ), требуемый уровень влажности и защиту от выветривания.

ГМ, вмещающий ПГВ комплекса, сложен мерзлыми многократно переслаивающимися мелкими и пылеватыми песками мощностью от 2 до 10-15 м, а также такого же типа супесями, средними и тяжелыми суглинками с мощностью отдельных пропластков от 0,1 до 1-2 м.

Естественная температура пород составляет $-2,5 . . .-3{ }^{\circ} \mathrm{C}$; суммарная влажность $15,1 . .20 \%$; объемный вес $1,83 \ldots 2,12$ г/ $\mathrm{cm}^{3}$, коэффициент пористости $0,45 \ldots 0,87$.

Механические свойства мерзлых пород: предел прочности на одноосное сжатие $-8,0 . .25,0$ кг/ $\mathrm{cm}^{2}$; предел прочности на растяжение $-1,5 . . .4,5$ кг/ $\mathrm{cm}^{2}$; эквивалентное сцепление $-3,5 . . .12,5 \mathrm{kг} / \mathrm{cm}^{2}$.

По категории крепости (СНиП IV.5.82) породы относятся к группе мерзлых грунтов «В».

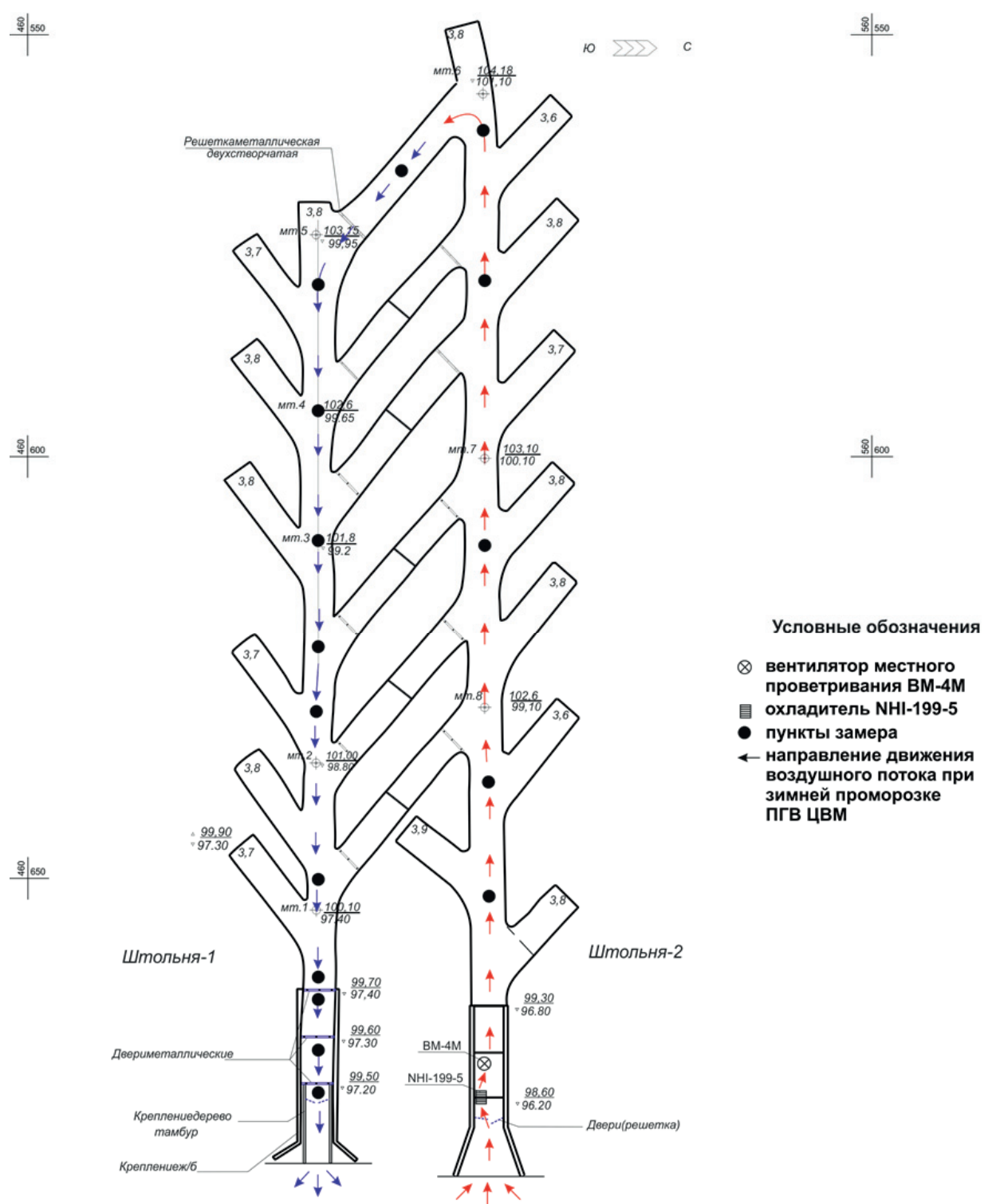

Pис. 1. Схема ПГВ ЦВМ. Приведены пункты замера температурных параметров

Fig. 1. Scheme of underground digging of «The Kingdom of the Eternal Frost». Points for measuring temperature parameters
Теплофизические свойства мерзлых пород: объемная теплоемкость $-460 . . .482$ ккал/м³ град; коэффициент теплопроводности $-1,26 . . .2,69$ ккал/м ч град; коэффициент температуропроводности $-27,2 . .53,2 \cdot 10^{-4} \mathrm{M}^{2} /$ ч

При оттаивании мерзлые дисперсные породы практически теряют прочностные свойства и характеризуются следующими скоростями теплового разрушения (по ИИГХИ-ПХВП-85): глина сильнопесчаная - 0,015...0,026 м/ч; песчаные разности $-0,0018 \ldots 0,0063 \mathrm{~m} /$ ч.

На всех дверях тамбуров штолен установлены ширмы, сшитые из палаточной ткани, для ограничения поступления теплого воздуха в период посещения комплекса экскурсантами.

Глазировка ПГВ не производилась с 2014 г. В отсутствии крепи, в результате выветривания пород, в кровле некоторых ПГВ ЦВМ в 2014-2017 гг. произошло три вывала. Самый кру- 


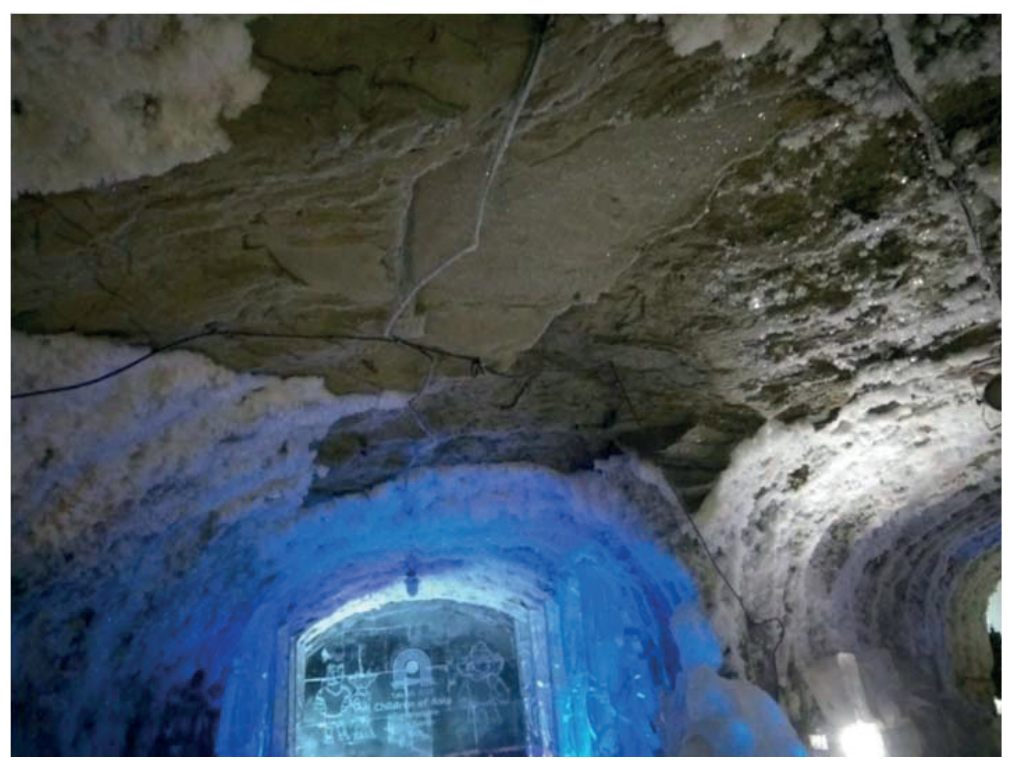

Рис. 2. Вывал пород кровли в районе сопряжения штольни 1 и калеры 4 ЦВМ

Fig. 2. Rocks of the roof were excavated near the tunnel 1 and chamber 4 of "The Kingdom of the Eternal Frost»

пный из них (весом около 200 кг) произошел на сопряжении штольни № 1 с камерой № 4. В настоящее время в зоне вывала наблюдаются протяженные трещины (рис. 2).

Как известно, устойчивость ПГВ криолитозоны, пройденных в мерзлых дисперсных породах, во многом определяется их температурным режимом и интенсивностью массообменных процессов $[1,2]$.

Температурный режим ПГВ ЦВМ в течение года формируется в результате совместного действия многих факторов: сезонного изменения температуры и влажности атмосферного воздуха; солнечной радиации на поверхность склона и устьевые части штолен; скорости, дебета, температуры и влажности воздушного потока в период зимней хладозарядки; интенсивности воздухообмена в период открывания входных дверей тамбуров; теплопритоков от экскурсантов, осветительных приборов, отапливаемого входного помещения; искусственного холода, вырабатываемого холодильными машинами в летний период.

\section{Методика исследования температурного режима цВМ}

Исследования температурного режима проводились в декабре 2017 г. и январе 2018 г. по методике $[3,4]$. Замеры температуры воздушной среды осуществлялись прибором CENTER-314, контактного слоя пород - приборами Testo 845 и LeicaDistoD8. Пункты замеров располагались начиная от тамбуров и далее по длине обоих штолен (рис. 1).

Измерения производились при закрытых дверях тамбуров, включенных осветительных прибоpax, неработающей холодильной установке, отсутствии вентиляции и присутствии незначительного количества экскурсантов. Хладозарядка ПГВ не осуществлялась. Температура наружного воздуха составляла $-42^{\circ} \mathrm{C}$.

Результаты проведенных наблюдений приведены на рис. 3. Обобщая их, можно сделать заключение, что, как и следовало ожидать, наиболее низкие температуры воздушной среды зафиксированы в тамбурах, а затем этот параметр постепенно повышается по длине ПГВ, достигая максимального значения в сбойке между штольнями.

Наиболее низкая температура контактного слоя пород зафиксирована в устье штольни-2 $\left(-8,7^{\circ} \mathrm{C}\right)$, она отличалась от температуры воздуха на $2{ }^{\circ} \mathrm{C}$. Затем этот показатель повышался по длине штольни и также незначительно отличался от температуры воздуха.

Замеры влажностных параметров воздушной среды не производились, но проведенные наблюдения позволяют сделать предположение, что в ПГВ происходят как конденсационные, так и испарительные процессы, причем последние явно превалируют. В результате этого происходит сублимация ледяной глазировки, ледовых скульптур и, не исключено, шлирового льда, а также активное иссушение (выветривание) приконтурного массива пород и его самопроизвольная дезинтеграция при отсутствии цементирующего льда (рис. 4).

Анализ результатов проведенных кратковременных наблюдений в определенной степени позволяет сделать следующие предварительные выводы.

Установившийся температурный режим в ПГВ ЦВМ можно считать оптимальным в плане обеспечения их устойчивости и комфортных условий экскурсантов. В то же время для предотвращения пластичных деформаций ледовых скульптур желательно обеспечение пониженных температур воздушной среды в пределах $-11 . . .-12{ }^{\circ} \mathrm{C}$. 

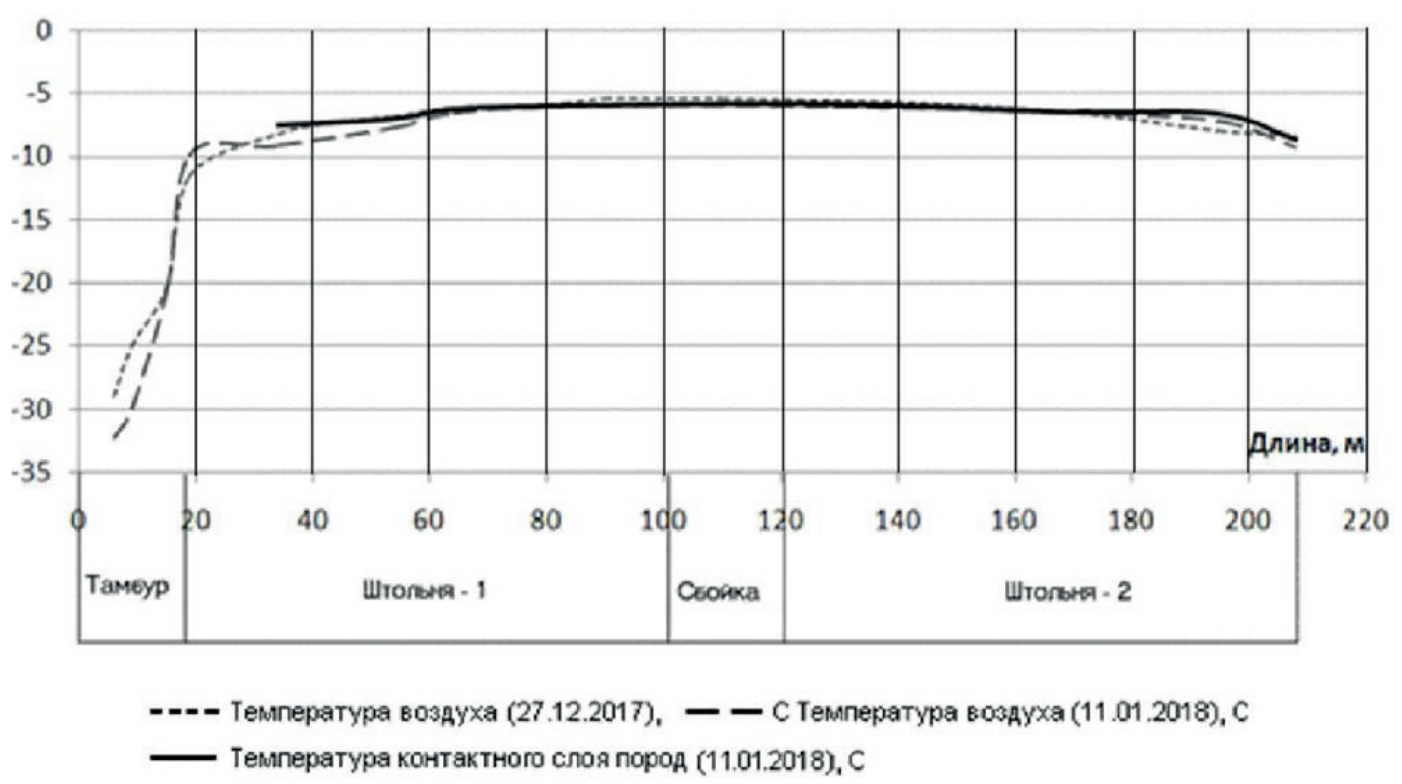

Рис. 3. Динамика значений температур воздуха и контактного слоя пород в выработках ЦВМ

Fig. 3. Dynamics of temperature values of air and contact layer of rocks in the workings of "The Kingdom of the Eternal Frost»

Проведенное обследование ПГВ с наличием изморози и толстого контактного слоя выветрелых пород не позволило выявить отслоения самыми простыми методами - звуковым и вибрационным $[5,6]$, так что не исключено, что кроме ранее обнаруженных обрушений кровли и видимых трещин с небольшим раскрытием, отдельные отслоения неразличимы и могут быть и в других местах, в настоящее время недоступных для обзора. Проведенными исследованиями с использованием георадара их не удалось обнаружить, так же, как и наличие ледяных шлиров.

Продолжительный период безремонтной эксплуатации ЦВМ, произошедшие обрушения кровли ПГВ при отсутствии крепи позволяют сделать предположение о возможном начавшемся нарушении стабильного состояния вмещающего ГМ, а также междукамерных целиков в геомеханиче- ском плане, как это произошло, например, в подземном холодильнике АО «Якутэнерго» $[7,8]$.

По результатам проведенных исследований сделан вывод о необходимости стабилизации технического состояния подземного комплекса и проведения поэтапных масштабных ремонтных работ. В этих целях разработаны рекомендации по креплению и регулированию теплового режима ПГВ ЦВМ.

В первую очередь должны быть выполнены работы по снятию наиболее выветрелого приконтактного слоя пород с поверхностей ПГВ, закреплены сопряжения, имеющие повышенные пролеты и наиболее подверженные горному давлению. Также подлежат креплению выявленные зоны, склонные к вывалообразованию [9].

Расчеты крепления ПГВ были выполнены по известным методикам [10-14]. На их основе разработаны паспорта крепления.

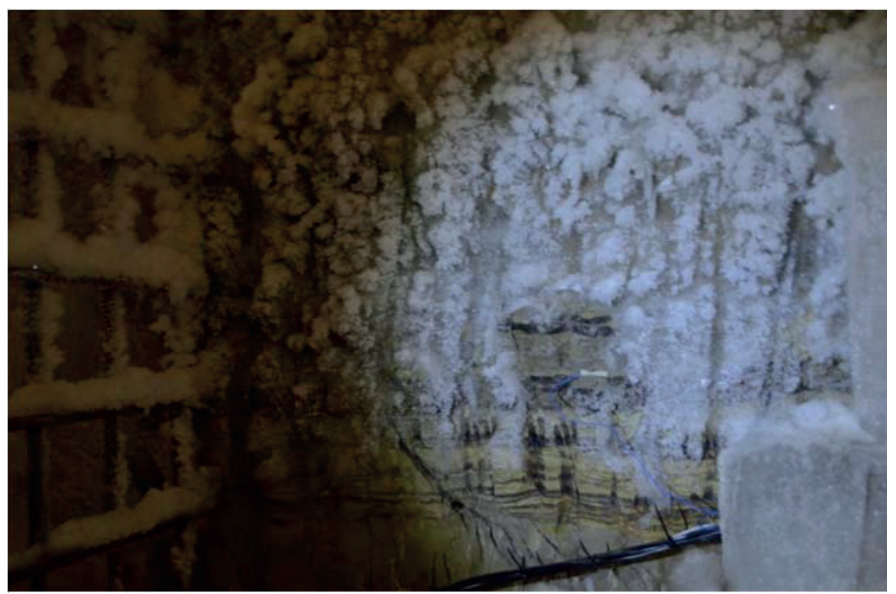

Pис. 4. Выветрелый борт горной выработки ЦВМ с установленным температурным датчиком

Fig. 4. Weathered board of the mining of «The Kingdom of the Eternal Frost» with an established temperature sensor 
Места крупных вывалов на сопряжении штольни № 1 и камеры № 2, камеры № 4, а также на сопряжении штольни № 2 и камеры № 12 рекомендуется крепить жесткой металлической рамной крепью. Материал крепи - двутавр № 10 и № 18 или спецпрофиль СВП-17. Соединить элементы крепи в стык методом электродуговой сварки. Затяжка кровли и бортов выработки должна производиться обрезной доской толщиной 50 мм. Забутовку закрепного пространства производить круглым лесом диаметром 15-20 см. Все остальные ПГВ ЦВМ должны быть закреплены анкерной крепью с затяжной сеткой Рабица.

Из существующих видов анкерных крепей для горнотехнических условий объекта рекомендуется выбрать беззамковые конструкции с активным радиальным распором закрепляемой части. Например, запрессовываемые в скважину фрикционные трубчатые анкера типа Split-Set и Swellex, закрепляемые расширяющимися составами. Их преимуществами являются: высокая скорость установки; надежность крепления и универсальность применения; нагружение анкера до рабочей нагрузки возможно сразу после его установки и равнопрочно с грузонесущим стержнем [15-23]. Наиболее подходящими для рассматриваемых условий являются фрикционные анкера системы «сплит-сет» (Split-Set).

При диаметре шпура 42 мм рекомендуется анкер Split-Set с диаметром трубки 47 мм. Согласно выполненным расчетам, анкера предлагается устанавливать по сетке $0,5 \times 0,5 \mathrm{~m}$.

Кровля выработок на закрепленных участках затягивается сеткой Рабица, прокладываемой под опорные плиты анкеров. Наиболее предпочтительна сетка Рабица в полимерном покрытии с ячеей
$40 \times 40$ мм. Диаметр проволоки вместе с покрытиeм - 2,8-3 мм.

Все работы должны выполняться поэтапно в зимний период в соответствии с прилагаемыми инструкциями.

Обеспечение устойчивого круглогодичного отрицательного ТР ЦВМ в требуемых параметрах, так же как и подземных холодильников криолитозоны, должно осуществляться комбинированным способом с использованием как естественного, так и искусственного холода и базироваться на максимальном использовании как атмосферного, так и накопленного горными породами холода [9].

Выполнение мероприятий по регулированию температурного режима заключается в проведении ежегодной зимней хладозарядки принудительно нагнетаемым холодным атмосферным воздухом, а также в выработке искусственного холода холодильными установками в летний период для компенсации всех видов теплопритоков.

Для предотвращения деформаций ледовых скульптур в следствие текучести льда при температурах выше $-10{ }^{\circ} \mathrm{C}$ в ЦВМ в течение года желательно поддерживать температуру не выше $-11 \ldots-12^{\circ} \mathrm{C}$.

Особое внимание должно быть уделено вопросам регулирования влажностного режима, т. к., как уже говорилось, он является определяющим в плане предотвращения выветривания шлирового льда и контактного слоя пород ПГВ с потерей их устойчивости. Результаты проведенных натурных наблюдений свидетельствуют, что толщина глазировки (50 мм), ежегодно наносимой на поверхности ПГВ, явно недостаточна. Согласно с номограммой, представленной на рис. 5, этот параметр дол-

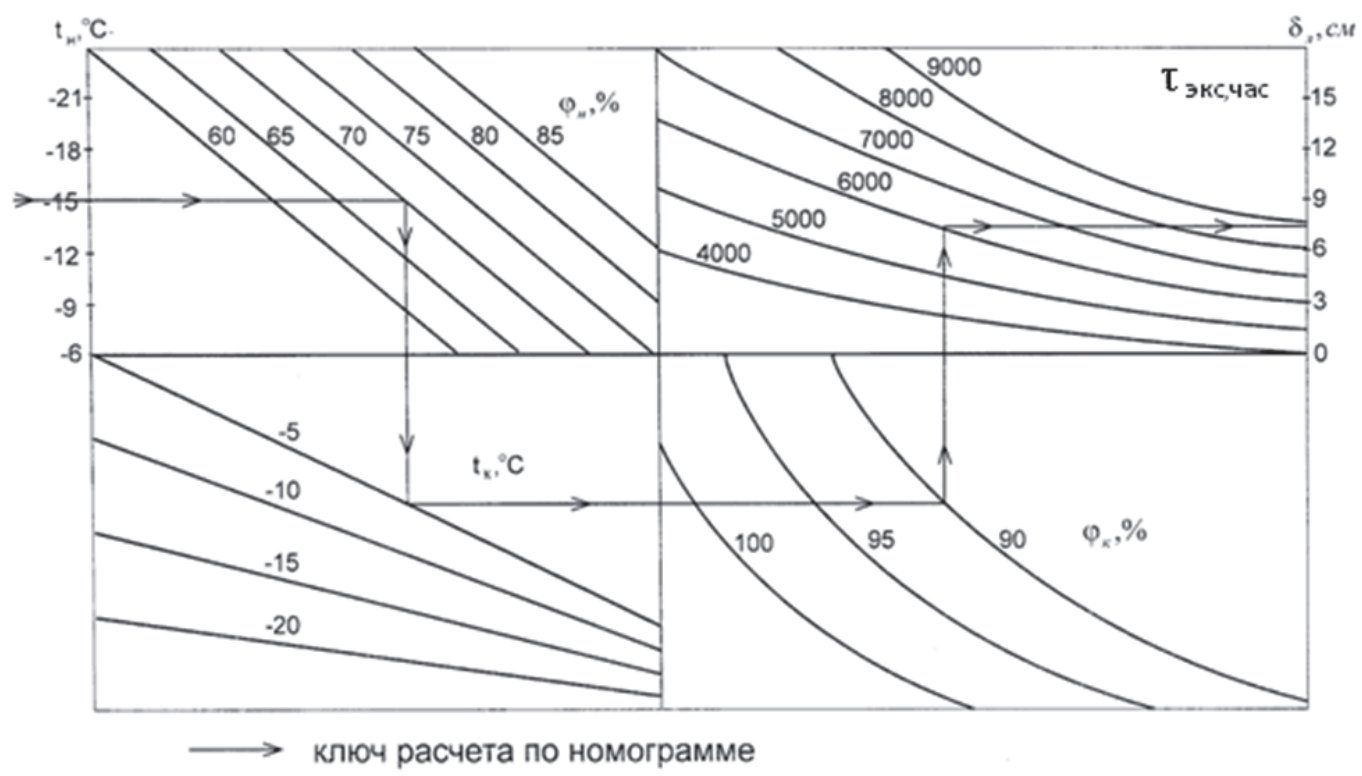

Рис.5. Номограмла определения толщины ледяной глазировки в зависимости от начальных и конечных значений относительной влажности ( $\varphi_{\mathrm{H}}$ и $\left.\varphi_{\mathrm{\kappa}}\right)$ и темлературы воздуха $\left(t_{\mathrm{H}}, t_{\mathrm{\kappa}}\right)$

Fig. 5. Nomogram of determination of ice glazing thickness depending on initial and final values of relative humidity $\left(\varphi_{\mathrm{H}}\right.$ and $\left.\varphi_{\mathrm{k}}\right)$ and air temperatures $\left(t_{\mathrm{H}}, t_{\mathrm{K}}\right)$ 
жен быть не менее 80 мм. Глазировкой должны быть покрыты все, включая закрепленные, поверхности ПГВ, с её ежегодным возобновлением в зимний период.

Расчет температурного режима ЦВМ и требуемой мощности холодильных машин выполнен с применением разработанного в лаборатории горной теплофизики ИГДС СО РАН программного комплекса MuseumCVM [7]. Принцип работы программного комплекса основан на использовании разработанной трехмерной математической модели теплообменных процессов в штольне, позволяющей осуществить долгосрочный прогноз в зависимости от различных конструктивных и технологических параметров: геометрических размеров и глубины заложения штольни, угла откоса горного склона, теплофизических свойств вмещающих пород, режима эксплуатации (поточность туристов, количество электроламп), режима хладозарядки (время года, температура подаваемого воздуха, интенсивность вентиляции), режима использования холодильного оборудования.

Задача по расчету температурного режима штольни ЦВМ заключается в определении на каждом временном шаге: распределения температуры воздуха внутри штольни; распределения температуры в массиве горных пород вокруг штольни; тепловой нагрузки на холодильное оборудование; энергетических затрат на вентиляцию и на выработку искусственного холода, общих эксплуатационных энергозатрат.

При разработке математической модели тепловых процессов, происходящих внутри штольни и в ГМ, окружающем ее, приняты следующие упрощающие допущения:

1) воздух внутри выработки хорошо перемешивается; его температура усредняется во время вентиляции по поперечному сечению, а при отключенной вентиляции по всему объему;

2) теплопритоки в штольню поступают только от окружающего ГМ, электроламп и экскурсантов.

Программный комплекс разработан в среде программирования Visual Studio 2010 и работает в диалоговом режиме в качестве приложения к операционным системам Microsoft Windows.

Расчеты проведены для климатических условий г. Якутска. Исходные данные взяты из отчёта результатов исследований, проведенных Центральной поисково-съемочной экспедицией ПГО «Якутскгеология» в 1989 г.

Расчеты были проведены при различных нижеперечисленных вариантах регулирования температурного режима ПГВ:

- естественный режим, при котором отсутствует регулирование температурного режима (без хладозарядки и использования холодильных установок);

- осенняя хладозарядка без использования искусственного холода;

- весенняя хладозарядка без использования искусственного холода;
- осенне-весенняя хладозарядка без использования искусственного холода;

- осенне-весенняя хладозарядка с использованием искусственного холода.

Поточность экскурсантов принимается в следующем количестве:

- летом 50 чел/сутки;

- зимой 20 чел/сутки;

- каждый экскурсант находится в ЦВМ в течение 1 часа.

В штольне установлены 25 электроламп мощностью по 40 Вт, которые включены в течение 8 часов в сутки. Хладозарядка атмосферным воздухом в весенний и осенний периоды проводится с интенсивностью $15 \mathrm{~m}^{3} /$ с в течение 12 часов в сутки. Для сохранности ледовых фигур необходимо поддерживать температуру воздуха в штольне не выше $-8 . . .-11{ }^{\circ} \mathrm{C}$.

Расчеты показали, что при всех вариантах регулирования ТР происходит снижение средней температуры воздуха в ЦВМ. При этом хладозарядка, проведенная только весной (с конца марта в течение 20 суток), недостаточна и не обеспечивает поддержания требуемой температуры хранения ледовых фигур как летом, так и зимой. А при осенней хладозарядке (с конца октября в течение 20 суток) только в зимние месяцы удается поддерживать температуру ниже $-8{ }^{\circ} \mathrm{C}$. Таким образом, для сокращения энергозатрат на выработку искусственного холода в летний период необходимо проведение ежегодных хладозарядок и осенью, и весной. В период экстремально низких температур хладозарядка нежелательна, во избежание морозобойного растрескивания приконтурного слоя пород ПГВ.

На рис. 6 представлена динамика изменения средней температуры воздуха в штольне при осенне-весенней хладозарядке и выработке искусственного холода на третьем году эксплуатации ЦВМ. Из приведенных графиков видно, что если поддержание температуры $-8{ }^{\circ} \mathrm{C}$ обеспечивается работой холодильных установок только в летнее время, то для поддержания температуры $-11{ }^{\circ} \mathrm{C}$ необходима их эксплуатация как летом, так и зимой.

Мощность холодильных установок $\left(N_{\text {хол }}\right)$, необходимая для поддержания требуемой температуры воздуха в ПГВ ЦВМ, рассчитана по величине поступающих теплопритоков. В летний период в этих целях рекомендована холодильная установка, оснащенная компрессором BITZER Ecoline 4HE-18Y-40Р, при выборе данного компрессора были учтены соотношения цены и качества. Техническая характеристика компрессора представлена в таблице.

Полугерметичный поршневой холодильный компрессор BITZER Ecoline 4HE-18Y-40Р используется в холодильных установках, системах холодоснабжения, системах кондиционирования воздуха. Компрессоры серии Ecoline оптимизированы для работы с хладагентом R $134 \mathrm{a}$, также могут использоваться R404A, R407C, R507A, R22. 

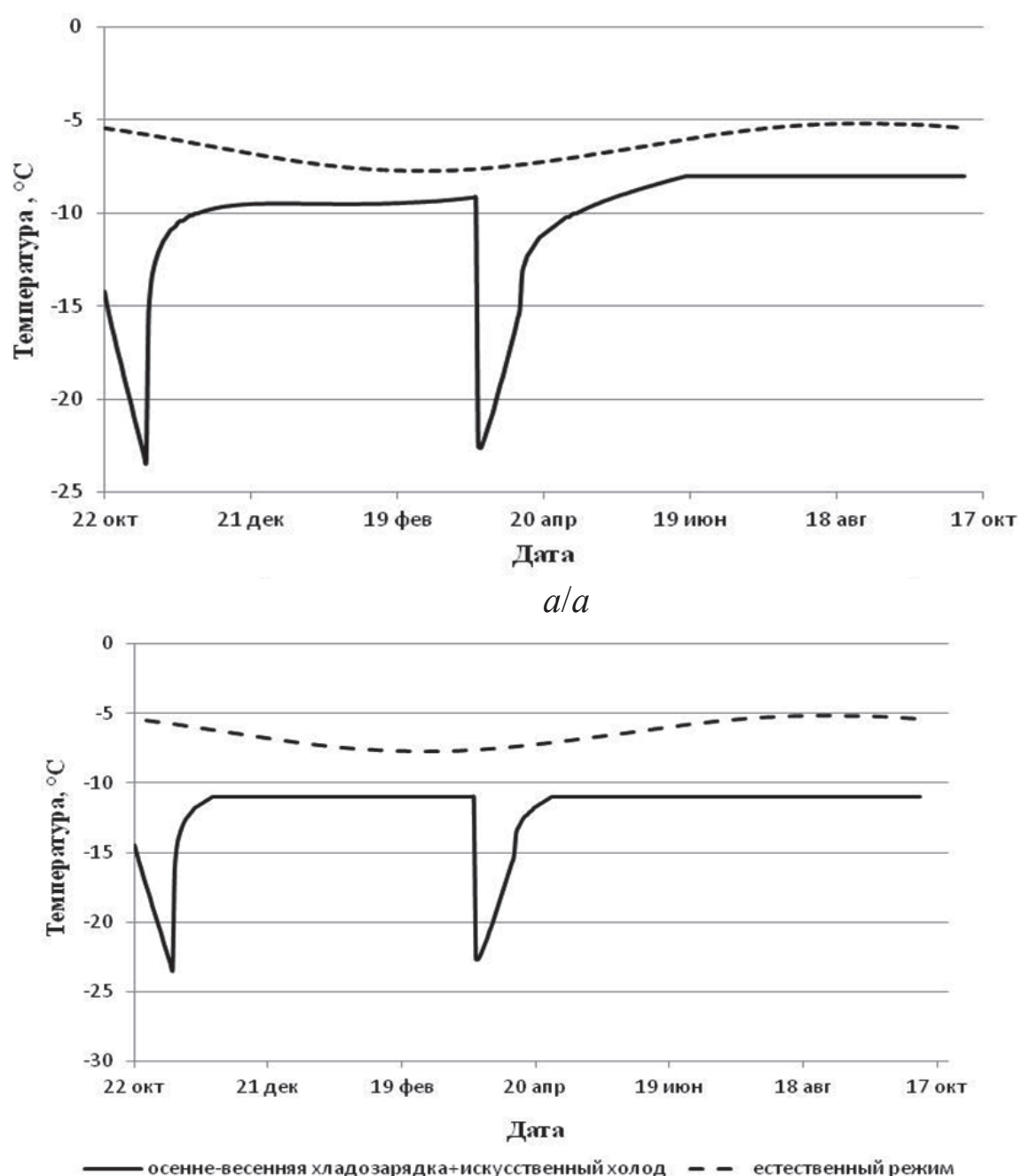

$\sigma / b$

Pис.6. Значения средних температур воздуха в штольне при осенне-весенней хладозарядке и выработке искусственного холода: а) $-8^{\circ} \mathrm{C} ;$ б) $-11^{\circ} \mathrm{C}$ (третий год эксплуатаиии ЦВМ)

Fig. 6. Mean air temperatures in the tunnel during autumn-spring cooling and artificial cooling: $\left.a)-8^{\circ} \mathrm{C} ; b\right)-11^{\circ} \mathrm{C}\left(3^{\text {rd }}\right.$ years of operation of The «Kingdom of the Eternal Frost»)

Tаблииа. Техническая характеристика компрессора BITZER Ecoline 4HE-18Y-40P

Table. $\quad$ Technical characteristic of the BITZER Ecoline 4HE18Y-40P compressor

\begin{tabular}{|l|c|}
\hline Вес нетто, кг/Net weight, kg & 183 \\
\hline $\begin{array}{l}\text { Холодопроизводительность (EN12900), кВт } \\
\text { Соoling сарасіty (ЕN12900), kW }\end{array}$ & 38,8 \\
\hline Диапазон холодопроизводительности (EN 12900), кBт & $35-40$ \\
\hline $\begin{array}{l}\text { Range of refrigerating сарасіty (EN 12900), kW } \\
\text { Максимальный ток двигателя } \\
\text { Maхimum motor current MCC, A }\end{array}$ & 36,7 \\
\hline Электропотребление/Power consumption & $\begin{array}{c}\Delta / \mathrm{Y} 220 . .240 \\
\Delta / 380 . .420 \\
\text { Y/3/50 }\end{array}$ \\
\hline Количество цилиндров/Number of cylinders & 4 \\
\hline Диапазон температур кипения/Boiling range & $0 /-40{ }^{\circ} \mathrm{C}$ \\
\hline Нагнетательный патрубок/Discharge pipe & $15 / 8 »$ \\
\hline Всасывающий патрубок/Suction pipe & $21 / 8 »$ \\
\hline Уровень шума/Noise level, dBA & 78 \\
\hline Аналог из старой версии/Analogue from the old version & $4 \mathrm{HC}-18.2 \mathrm{Y}$ \\
\hline Холодильный коэффициент/Refrigeration coefficient & 2,3 \\
\hline
\end{tabular}

Дальнейшая эксплуатация ЦВМ и регулирование температурного режима должны производиться в соответствии с инструкциями, разработанными ИГДС для подземных холодильников $[5,6]$.

\section{Заключение}

Для обеспечения долговременной безопасной эксплуатации ЦВМ необходим периодический геомеханический контроль за состоянием ГМ, вмещающего ПГВ, и смещениями их кровли по методике ВНИМИ [24, 25]. Инструментальные наблюдения позволят фиксировать смещения блоков, образование заколов и отслоений, интенсивность образования и роста трещин, что несомненно будет способствовать предотвращению аварийных ситуаций. Кроме этого, для оперативного контроля состояния приконтурного ГМ ПГВ, закрепленных анкерной крепью, может быть рекомендована установка серийно изготавливаемых глубинных реперов (РГ-1, РГ-2, РГ-3), снабженных цветовы- 
ми индикаторами, которые хорошо зарекомендовали себя на шахтах и рудниках. Положение цветовых полос и скорости смещения индикаторов должно периодически контролироваться для выявления тенденций развития деформаций ГМ на ранней стадии.

В выявленных трещинах в ГМ для определения скорости их раскрытия могут быть установлены датчики, разработанные ИГДС. Для получения более полной информации о происходящих геомеханических процессах в породах кровли может быть также рекомендована установка акустических датчиков [7]. Контроль степени раскрытия трещин и роста интенсивности акустических импульсов,

\section{СПИСОК ЛИТЕРАТУРЫ}

1. Saiied M. Aminossadati, Nayeemuddin M. Mohammed, Javad Shemshad. Distributed temperature measurements using optical fibre technology in an underground mine environment// Tunnelling and Underground Space Technology. - 2010. - V. 25. P. $220-229$.

2. Melnikov P.I., Pavlov A.V. Study of permafrost in the U.S.S.R.: Scientific and practical problems // Cold Regions Science and Technology. 1982. V.6. - P. 163-171.

3. Дядькин Ю.Д. Основы горной теплофизики для шахт и рудников Севера. - М.: Недра, 1968. - 255 с.

4. Дядькин Ю.Д., Шувалов Ю.В. Тепловые съемки и тепловой расчет шахт и рудников. - Л.: Изд-во ЛГИ, 1997. - 88 с.

5. Инструкция по безопасным методам работы на подземных холодильниках объединения «Якутрыб̆ром». - Якутск: Изд-во ЯФ С0 АН СССР, 1987. - 32 с.

6. Рекомендации по строительству, реконструкции и эксплуатации подземных холодильников в Якутской АССР. - Якутск: Изд-во ЯФ СО АН СССР, 1982. - 49 с.

7. Курилко А.С. и др. Регулирование теплового режима подземных сооружений складского и специального назначения в условиях Севера. - Якутск: Изд-во Ин-та Мерзлотоведения СО PAH, 2011. -246 c.

8. Курилко А.С., Хохолов Ю.А. Влияние режимов эксплуатации горных выработок на температурно-влажностное состояние вентиляционного воздуха и массива горных породу в условиях криолитозоны // Горный информационно-аналитический бюллетень (научо-технический журнал). - 2016. - S21. C. $476-485$.

9. Хохолов Ю.А., Курилко А.С., Киселев В.В., Романова Е.К. К вопросу повышения эффективности строительства и эксплуатации подземных сооружений криолитозоны различного назначениях // Евразийское научное объединение. - 2018. № 1 (35). - С. $65-67$.

10. Территориальные строительные нормы 31-323-2002 Республики Саха (Якутия). Подземные объекты в горных выработках криолитозоны Якутии. - Якутск, 2002. - 24 с.

11. Шехурдин В.К. Задачник по горным работам, проведению и креплению выработок. - М.: Недра, 1985. - 240 с.

12. Строительные нормы и правила II-94-80. Подземные горные выработки. - М.: ФГУП ЦПП, 2004. - 28 с. проводимый совместно с измерениями смещений кровли, позволит в полной мере оценить геомеханическое состояние техногеннонарушенного ГМ, вмещающего ПГВ ЦВМ, разработать дополнительные превентивные мероприятия по предотвращению негативных процессов. Для сокращения энергозатрат на выработку искусственного холода в летний период рекомендовано проводить ежегодные осеннюю и весеннюю хладозарядки принудительной вентиляцией.

Таким образом, при тщательном и своевременном выполнении всех рекомендуемых мероприятий может быть обеспечена длительная безремонтная и безопасная эксплуатация ЦВМ.

13. Гелескул М.Н., Хорин В.Н., Киселев Е.С., Бушуев Н.П. Справочник по креплению горных выработок. - М.: Недра, 1972. $368 \mathrm{c.}$

14. Гребенюк В.А., Пыжьянова Я.С., Ерофеева И.Е. Справочник по горнорудному делу. - М.: Недра, 1983. - 816 c.

15. Kömürlü E., Kesimal A., Çolak Ü. Polyurea type thin sprayon liner coating to prevent rock bolt corrosion // Proceedings of the ISRM International Symposium - $8^{\text {th }}$ Asian Rock Mechanics Symposium. - Sapporo, 2014. - P. 1389-1397.

16. Тимофеев П.В. Крепление горных выработок технологией Swellex // Горный информационно-аналитический бюллетень. - 2012. - № 9. - С. 193-195.

17. Charlie C.L. Analysis of Inflatable Rock Bolts // Rock Mechanics and Rock Engineering. - 2016. - V. 49. - P. 273-289.

18. Dingxiang Zou. Ground Reinforcement and Support // Theory and Technology of Rock Excavation for Civil Engineering. - Singapore: Mettallurgical Industrie Press, 2016. - P. 579-637.

19. Darling P. SME Mining Engineering Handbook. $3^{\text {rd }}$ ed. - Englewood: Society for Mining, Metallurgy and Exploration, 2011. $1840 \mathrm{p}$.

20. Luo J., Haycocks C., Karmis M. Overview of U.S. rock bolting // Coal International. - 2001. - V. 249. - Iss. 1. - P. 30-33.

21. Wijk G. Mining improvement with Swellex // International Journal of Rock Mechanics and Mining Sciences \& Geomechanics Abstracts. - 1985. - V. 22. - P. A22-A26.

22. Yan Xing, P.H.S.W. Kulatilake, L.A. Sandback. Effect of rock mass and discontinuity mechanical properties and delayed rock supporting on tunnel stability in an underground mine // Engineering geology. - 2018. - V. 238. - P. 62-75.

23. Hedensjo H. Swellex rock bolting system // International Journal of Rock Mechanics and Mining Sciences \& Geomechanics Abstracts. - 1987. - V. 24. - P. A25-A27.

24. Методические указания по исследованию горного давления на угольных и сланцевых шахтах. - Л.: ВНИИМИ, 1970. - 302 с.

25. Строительные нормы и правила11-02-96. Инженерные изыскания для строительства. Основные положения. - М.: Минрегион России, 1997. - 187с.

Поступила 20.02.2019 2. 
Информация об авторах

Петров А.Н., кандидат технических наук, заведующий кафедрой горного дела Северо-Восточного федерального университета им. М.К. Аммосова.

Kuселев B.B., кандидат технических наук, старший научный сотрудник лаборатории горной теплофизики Института горного дела Севера им. Н.В. Черского Сибирского отделения Российской Академии наук.

Романова E.K., кандидат технических наук, научный сотрудник лаборатории горной теплофизики Института горного дела Севера им. Н.В. Черского Сибирского отделения Российской Академии наук.

Сивиева А.И., аспирант, старший преподаватель кафедры горного дела Северо-Восточного федерального университета им. М.К. Аммосова. 


\title{
ON THE ISSUE OF SAFE OPERATION OF THE UNDERGROUND TRAVEL COMPLEX «THE KINGDOM OF ETERNAL FROST»
}

\section{Andrey N. Petrov',}

petrow_andrei@mail.ru

Valery V. Kiselev²,

helconst@mail.ru

\section{Elena K. Romanova², helconst@mail.ru}

\author{
Alena I. Sivtseva', \\ alyona_archibald@mail.ru \\ 1 M.K Ammosov North-Eastern Federal University, \\ 58, Belinsky street, Yakutsk, 677000. \\ ${ }^{2}$ N.V. Chersky Institute of Mining of the North Siberian Branch of the Russian Academy of Sciences, \\ 43, Lenin street, Yakutsk, 677000.
}

Relevance. Investigations of the thermal regime and development of effective ways of controlling it in underground structures of various purposes have received considerable attention in recent years. This is related not only to intensification of underground space development, but also to the variety of thermal conditions and the degree of influence of the temperature factor on the efficiency and safety of construction and operation of underground structures. As it is known from the mining practice in the North, the thawed rock mass, especially above the roof of the excavations, creates significant loads on the supports, sometimes exceeding permissible, which causes irreversible deformations, and sometimes leads to its collapse.

Objects: galleries of the tourist complex «The Kingdom of Eternal Frost» located on the $5^{\text {th }} \mathrm{km}$ of the Vilyuisk tract of Yakutsk.

The aim of the research is to develop the measures to ensure the required technical condition of the thermal regime complex and recommendations for securing underground mining workings providing safe conditions for tourists to stay.

Methods: studies of the temperature regime, visual inspection of the mining slope and underground mine workings of the tourist complex, selection of the type of fastening for the required conditions, calculation of the fastening parameters.

The paper introduces the results of the studies of the thermal regime of underground mine workings during winter operation period, the results of a visual survey of the mining slope and underground mine workings. The authors give recommendations to ensure the stability and anchoring of the zones for formation of underground mining excavations of the tourist complex «The Kingdom of Eternal Frost». The calculation of the temperature mode of the digital computer and the required power of the refrigerating machines was carried out using the MuseumCVM software package developed at the Laboratory of Mining Thermophysics of the Institute of Mining of the North named after N.V. Chersky. To reduce energy consumption for producing artificial cold in summer, it is recommended to hold annual refrigerated charge in autumn and spring.

\section{Key words:}

Cryolithozone, underground mining, permafrost, temperature regime, mountain massif, refrigeration, glazing, field observations, fastening of mine workings, anchor support, frame support, mating of mine workings.

\section{REFERENCES}

1. Saiied M.Aminossadati, Nayeemuddin M.Mohammed, Javad Shemshad. Distributed temperature measurements using optical fibre technology in an underground mine environment. Tunnelling and Underground Space Technology, 2010, vol. 25, pp. $220-229$.

2. Melnikov P.I., Pavlov A.V. Study of permafrost in the U.S.S.R.: Scientific and practical problems. Cold Regions Science and Technology, 1982, vol. 6, pp. 163-171.

3. Dyadkin Yu.D. Osnovy gornoy teplofiziki dlya shakht i rudnikov Severa [Basics of mining thermal physics for mines and mines of the North]. Moscow, Nedra Publ., 1968. 255 p.

4. Dyadkin Yu.D. Teplovye semki i teplovoy raschet shakht i rudnikov [Thermal surveys and thermal calculation of mines and mines]. Leningrad, LGI Publ., 1997. 88 p.

5. Instruktsiya po bezopasnym metodam raboty na podzemnykh kholodilnikakh obedineniya "Yakutrybprom» [Instructions for safe working methods on underground refrigerators of the Yakutrybprom association]. Yakutsk, YAF S0 AN SSSR Publ., 1987. 32 p.
6. Rekomendatsii po stroitelstuu, rekonstruktsii i ekspluatatsii podzemnykh kholodilnikov $v$ Yakutskoy ASSR [Recommendations for construction, reconstruction and operation of underground refrigerators in the Yakut ASSR]. Yakutsk, YAF S0 AN SSSR Publ., $1982.49 \mathrm{p}$.

7. Kurilko A.S. Regulirovanie teplovogo rezhima podzemnykh sooruzheniy skladskogo $i$ spetsialnogo naznacheniya $v$ usloviyakh Severa [Regulation of thermal regime of underground storage facilities for special purposes in the North]. Yakutsk, Institute of Permafrost SO RAN Publ., 2011. 246 p.

8. Kurilko A.S., Khokholov Yu.A. Vliyanie rezhimov ekspluatatsii gornykh vyrabotok na temperaturno-vlazhnostnoe sostoyanie ventilyatsionnogo vozdukha i massiva gornykh porod v usloviyakh kriolitozony [Influence of excavation on the temperature and moisture condition of the ventilation air and massive of mountain rocks in cryolitezone]. Mining informational and analytical bulletin, 2016, no. S21, pp. 476-485.

9. Khokholov Yu.A., Kurilko A.S., Kiselev V.V., Romanova E.K. $\mathrm{K}$ voprosu povysheniya effektivnosti stroitelstva i ekspluatatsii 
podzemnykh sooruzheniy kriolitozony razlichnogo naznacheniya [On the issue of improving the efficiency of construction and operation of underground structures of permafrost for various purposes]. Eurasian scientific association, 2018, no. 1 (35), pp. $65-67$.

10. Territorialnye stroitelnye normy 31-323-2002 Respubliki Sakha (Yakutiya). Podzemnye obekty v gornykh vyrabotkakh kriolitozony Yakutii [Territorial building codes 31-323-2002 of the Republic of Sakha (Yakutia). Underground objects in cryolithozone mining].Yakutsk, 2002. $24 \mathrm{p}$.

11. Shekhurdin V.K. Zadachnik po gornym rabotam, provedeniyu $i$ krepleniyu vyrabotok [Tasks on mining, conducting and fixing workings]. Moscow, Nedra Publ., 1985. 240 p.

12. Stroitelnye normy i pravila II-94-80. Podzemnye gornye vyrabot$k i$ [Building Norms and Rules II-94-80. Underground mining]. Moscow, FGUP CPP Publ., 2004. 28 p.

13. Geleskul M.N., Khorin V.N., Kiselev E.S., Bushuev N.P. Spra vochnik po krepleniyu gornykh vyrabotok [Mining Mounting Guide]. Moscow, Nedra Publ., 1972. 368 p.

14. Grebenyuk V.A., Pyzhyanova Ya.S., Erofeeva I.E. Spravochnik po gornorudnomu delu [Mining handbook]. Moscow, Nedra Publ., $1983.816 \mathrm{p}$.

15. Kämürlü E., Kesimal A., Çolak Ü. Polyurea type thin sprayon liner coating to prevent rock bolt corrosion. Proceedings of the ISRM International Symposium - $8^{\text {th }}$ Asian Rock Mechanics Symposium. Sapporo, 2014. pp. 1389-1397.

16. Timofeev P.V. Kreplenie gornykh vyrabotok tekhnologiey Swellex [Fastening mining developments by the Swellex technology]. Mining informational and analytical bulletin, 2012, no. 9, pp. 193-195.
17. Charlie C.L. Analysis of Inflatable Rock Bolts. Rock Mechanics and Rock Engineering, 2016, vol. 49, pp. 273-289.

18. Dingxiang Zou. Ground Reinforcement and Support. Theory and Technology of Rock Excavation for Civil Engineering. Singapore, Mettallurgical Industrie Press, 2016. pp. 579-637.

19. Darling P. SME Mining Engineering Handbook. $3^{\text {rd }}$ ed. Englewood, Society for Mining, Metallurgy and Exploration, 2011. $1840 \mathrm{p}$.

20. Luo J., Haycocks C., Karmis M. Overview of U.S. rock bolting. Coal International, 2001, vol. 249, Iss. 1, pp. 30-33.

21. Wijk G. Mining improvement with Swellex. International Journal of Rock Mechanics and Mining Sciences \& Geomechanics Abstracts, 1985, vol. 22, pp. A22-A26.

22. Yan Xing, Kulatilake P.H.S.W., Sandback L.A. Effect of rock mass and discontinuity mechanical properties and delayed rock supporting on tunnel stability in an underground mine. Engineering geology, 2018, vol. 238, pp. 62-75.

23. Hedensjo H. Swellex rock bolting system. International Journal of Rock Mechanics and Mining Sciences \& Geomechanics Abstracts, 1987, vol. 24, pp. A25-A27.

24. Metodicheskie ukazaniya po issledovaniyu gornogo davleniya na ugolnykh $i$ slantsevykh shakhtakh [Guidelines for the study of rock pressure in coal and shale mines]. Leningrad. VNIIMI Publ., 1970. $302 \mathrm{p}$.

25. Stroitelnye normy i pravila 11-02-96. Inzhenernye izyskaniya dlya stroitelstua. Osnounye polozheniya [Building codes 11-02-96. Engineering surveys for construction. Key Points]. Moscow, Minregion Rossii Publ., 1997. 187 p.

Received: 20 February 2019.

\section{Information about the authors}

Andrey N. Petrov, Cand. Sc., head of the Department of Mining, M.K Ammosov North-Eastern Federal University.

Valery V. Kiselev, Cand. Sc., senior researcher, Laboratory of Mountain Thermophysics, Institute of Mining of the North named after N.V. Chersky Siberian Branch of the Russian Academy of Sciences.

Elena K. Romanova, Cand. Sc, researcher of the Laboratory of Mining Thermophysics, Institute of Mining of the North named after N.V. Chersky Siberian Branch of the Russian Academy of Sciences.

Alena I. Sivtseva, graduate student, senior teacher, M.K Ammosov North-Eastern Federal University. 